\title{
REVISÃO BIBLIOMÉTRICA SOBRE FUSÃO E AQUISIÇÃO DE EMPRESAS NO BRASIL
}

\section{Resumo}

Objetivo do estudo: Analisar a produção acadêmica sobre Fusões e Aquisições (F\&A), em língua portuguesa no Brasil, por meio de uma revisão bibliométrica e integrativa, dada a importância dessas estratégias para o crescimento de empresas e o elevado número de ocorrências no país.

Método: Pesquisa exploratória, com revisão bibliométrica e de literatura integrativa em 68 artigos publicados de 2000 a 2018, encontrados na base Spell e no Portal de Periódicos da Capes.

Originalidade/relevância: Mesmo com o interesse e a importância das estratégias de F\&A para as empresas e a economia do país, não foram encontradas revisões bibliométricas ou integrativas sobre o tema, diferentemente do cenário internacional, em que há trabalhos sobre o panorama das pesquisas e interesses de estudos.

Principais resultados: Pesquisadores de diversas regiões estudam o tema sem a mesma intensidade de ocorrência das F\&A no país. Há certo grau de concentração de autores, periódicos e instituições, porém inconstantes no período estudado. Ao utilizar os programas Atlas TI ${ }^{\circledR}$ e VOSviewer®, foram encontrados quatro agrupamentos - Economia/Finanças, Estratégia, Gestão do Processo de F\&A e Cultura - que refletem as principais linhas temáticas e estão coerentes com a análise de cocitação que apontou o uso de referências internacionais/nacionais na perspectiva financeira, estratégica e de gestão. Destaca-se que apenas artigos mais recentes (2015-2018) citam outros autores, principalmente internacionais.

Contribuições teóricas: Apresentação de panorama integrativo das pesquisas de F\&A no Brasil, em língua portuguesa, com trajetória do tema, características, lacunas e assuntos ausentes, proposição de agenda de estudos, com vistas a pesquisas mais robustas e compreensão mais plural e interdisciplinar da temática.

Palavras-chaves: Fusões e aquisições. Revisão integrada da literatura Bibliometria.

\section{BIBLIOMETRIC REVIEW ON BUSINESS MERGER AND ACQUISITION IN BRAZIL}

Abstract

Objective: To analyze the academic production on Mergers and Acquisitions (M\&A), in Brazilian Portuguese, through a bibliometric and integrative review, given the importance of these strategies for the business growth and the high number of occurrences in the country.

Methodology: Exploratory research, with bibliometric and integrative literature in 68 articles published from 2000 to 2018, found in Spell database and Capes Periodicals Portal.

Originality/relevance: Even with the interest and importance of M\&A strategies for companies and the country's economy, no bibliometric or integrative reviews on the topic were found, unlike the international scenario, in which there are works on the research panorama and interests in studies. Main results: Researchers from different regions study the theme without the same intensity of occurrence of M\&A in the country. There is a certain degree of concentration of authors, journals and institutions, but inconstant in the investigated term. When using the Atlas TI® and VOSviewer® Management Process and Culture - which reflect the main thematic lines and are consistent with the cocitation analysis that pointed the use of international/national references in financial, strategic and management perspectives. It is noteworthy that only more recent articles (2015-2018) cite other authors, mainly international ones.

Theoretical contributions: Presentation of an integrative panorama of M\&A research in Brazilian Portuguese, with a trajectory of the theme, characteristics, gaps and missing subjects, proposal of a study agenda, in order to more robust research and a more plural and interdisciplinary understanding of the topic.

Keywords: Mergers and acquisitions. Integrated literature review. Bibliometry.

\section{REVISIÓN BIBLIOMÉTRICA SOBRE FUSIÓN EMPRESARIAL Y ADQUISICIÓN EN BRASIL}

\section{Resumen}

Objetivo: Analizar la producción académica sobre fusiones y adquisiciones (F\&A), en portugués en Brasil, a través de revisión bibliométrica y integradora, dada la importancia para el crecimiento de las empresas y la gran cantidad de F\&A en el país.

Método: La investigación fue exploratoria, con revisión bibliométrica e integradora en 68 artículos publicados entre 2000 y 2018, de la base SPELL y Portal de Revistas CAPES.

Relevancia/originalidad: Incluso con el interés y la importancia de las estrategias de F\&A para las empresas y para el escenario económico del país, no se encontraron revisiones bibliométricas o integradoras. A diferencia del escenario internacional, donde hay obras que reflejan el panorama de los intereses de investigación y estudio.

Resultados principales: Hay diferentes investigadores, en diferentes instituciones educativas, pero no con la misma intensidad que las F\&A en el país. Hay concentración de autores, revistas e instituciones, pero no hay constancia en la producción durante el período. Con el uso de Atlas TIß e VOSviewer $®$, fueran identificados $y$ analizados cuatro grupos: Economía/Finanzas; Estrategia; Gestión de procesos de F\&A; y Cultura que reflejan las principales líneas temáticas. Estas agrupaciones son consistentes con el análisis de cocitation, que apuntó el uso de referencias internacionales/nacionales con perspectiva financiera, estratégica y de gestión. Solo los artículos más recientes (2015-2018) citan mayor número de referencias, siendo internacionales.

Contribuciones teóricas: Se presentó una visión integradora en lengua portuguesa sobre F\&A en Brasil, la trayectoria del tema, características y los temas faltantes, con la propuesta de una agenda de investigación que permitirá una comprensión más plural e interdisciplinaria del tema.

Palabras clave: Fusiones y adquisiciones. Revisión bibliográfica integrada. Bibliometría.

\section{Cite as / Como citar}

American Psychological Association (APA)

Calil, M. R., Bueno, J. M., Domingues, C. R., \& Borges, J, F. (2020, Oct./Dec.). Revisão bibliométrica sobre fusão e aquisição de empresas no Brasil. Iberoamerican Journal of Strategic Management (IJSM), 19(4), 76-99. https://doi.org/10.5585/riae.v19i4.16310. 


\section{Introdução}

As Fusões e Aquisições (F\&A), reflexos de decisões estratégicas, impactam em outras estratégias e nas diretrizes empresariais, no que tange à busca de vantagens competitivas (Haeruddin, 2017). Esses processos também podem levar a uma rápida expansão, economia de escala, maior produtividade e obtenção de novos mercados, inclusive internacionais (Khan, Soundararajan, Wood, \& Ahammad, 2020). As estratégias de F\&A criam valor pela transferência de recursos e capacidades entre as organizações envolvidas, o que possibilita novas e diferentes combinações entre os elementos organizacionais (Graebner, Heimeriks, Huy, \& Vaara, 2017). Elas são, reconhecidamente, um método-chave para a obtenção de crescimento e o aumento de diversidade e lucratividade organizacionais (Haeruddin, 2017).

Nas últimas décadas, o Brasil sofreu mudanças significativas no contexto econômico, as quais favoreceram a ocorrência de F\&A, tornaram o país mais atrativo para investidores e estimularam organizações a vender ou adquirir outras, como forma de enfrentar os desafios de uma economia mais globalizada e interconectada (Bomfim \& Callado, 2016). Aqui, as estratégias de F\&A ganharam escala nos últimos anos, pois, de acordo com o relatório anual da consultoria PricewaterhouseCoopers (PwC) (2019), houve 912 transações de F\&A em 2019, com um aumento de 40\% em relação a 2018, quando ocorreram 658 transações. Esse resultado de 2019 se configurou como o recorde histórico, ao suplantar as 879 transações realizadas em 2014.

Para Ferreira e Callado (2015, p. 71), tais estratégias constituem eventos corporativos complexos e dinâmicos que geram o interesse de diferentes campos das Ciências Sociais. Ou seja, enquanto fenômeno, as F\&A proporcionam questões além da dinâmica econômico-financeira de uma companhia, pois dizem respeito aos movimentos do capital financeiro e industrial, além de aspectos socioculturais. Sob o ponto de vista dos estudos relativos à estratégia empresarial, as F\&A são vistas como excelentes opções para crescimento das empresas e ganhos, como aumento de participação no mercado e de escala, entrada em novos mercados, entre outros (Reis, Partyka, Lana, \& Marcon, 2018).

Diante disso, este artigo objetiva realizar uma revisão de literatura por meio da revisão bibliométrica combinada com a revisão integrativa, assim como analisar e sintetizar a produção científica da área de Administração entre 2000 e 2018, em língua portuguesa e no Brasil, cujas plataformas da Scientific Periodicals Electronic Library (Biblioteca Eletrônica de Periódicos Científicos, SPELL) e do Portal de Periódicos da Coordenação de Aperfeiçoamento de Pessoal de Nível Superior (CAPES) se sobressaíram como fontes de dados. O estudo se justifica pela importância das estratégias de F\&A para as organizações obterem crescimento e consolidação de mercado. Esse tipo de pesquisa é relevante, pois apresenta e discute atuais e novos quadros teóricos e perspectivas que podem surgir, com indicação de agenda para investigações futuras (Snyder, 2019).

Após a realização de uma pesquisa prévia em artigos de periódicos brasileiros, foram encontrados apenas três trabalhos que visaram fazer uma revisão acerca do tema no Brasil: um deles, publicado em 2015, foca na área de Gestão de Pessoas; outro, de 2018, trata especificamente de processos de F\&A no 
setor educacional mundial; e o terceiro é uma revisão sistemática de literatura. Dada a importância econômica e estratégica das F\&A nas últimas três décadas, elas se mostraram como uma das principais estratégias de entrada de empresas estrangeiras no Brasil, além de serem responsáveis por (re)arranjos setoriais (Camargos \& Barbosa, 2010; Ferreira \& Callado, 2015). Devido à complexidade e ao alto índice de insucessos (Binder, Maccari, \& Nasser-Carvalho, 2010), torna-se necessário aprofundar a temática no contexto brasileiro, com vistas a contribuir com a consolidação de conhecimentos obtidos até o momento e oferecer perspectivas de estudos futuros.

No cenário internacional, foram encontradas diferentes revisões de literatura sobre F\&A na área de Administração, sobretudo nos últimos cinco anos, tanto mais abrangentes, como os trabalhos de Shi, Sun e Prescott (2012), Ferreira, Santos, Almeida e Reis (2014) e Reddy (2015), quanto as revisões sobre temas específicos e relacionados às $\mathrm{F} \& \mathrm{~A}$, a exemplo da revisão sobre a integração após F\&A de Graebner et al. (2017) e a abordagem de negócios familiares de Worek (2017).

Convém salientar que o presente artigo foi estruturado em cinco seções: introdução; referencial teórico-empírico; procedimentos metodológicos; apresentação e discussão dos resultados; e conclusão.

\section{Referencial teórico-empírico}

Gestores são pressionados a adotar iniciativas para assegurar a criação ou manutenção de vantagens competitivas, e uma das técnicas mais comumente adotadas é a de F\&A (Haeruddin, 2017). Especificamente, a estratégia de fusão consiste em integrar a operação de duas empresas que constituem uma nova organização, enquanto as duas companhias originais deixam de existir. Já na aquisição, uma empresa adquire outra com o objetivo de aumentar o portfólio e a participação no mercado ou, ainda, se inserir em mercados nacionais ou internacionais (Hitt, Ireland, \& Hoskisson, 2014).

Para Khan et al. (2020), as F\&A não apenas aumentam as vantagens competitivas de uma organização, como também estimulam novas habilidades, capacidades e eficiências de valor específico para a expansão nacional e internacional. São importantes meios para a mudança e o crescimento organizacional e, de acordo com Welch, Pavićević, Keil e Laamanen (2020), apesar da falta de evidências empíricas da efetiva criação de valor para os acionistas, esse tipo de estratégia tem crescido a cada ano.

No Brasil, as estratégias de F\&A surgiram no início dos anos 1990 e se impulsionaram posteriormente, resultado de mudanças estruturais e estratégicas na economia brasileira, como as privatizações, a abertura e a desregulamentação de mercados que levaram empresas estrangeiras a entrar no mercado brasileiro por meio do referido método (Almada \& Policarpo, 2016; Vieira, Brito, Santana, Sanches, \& Galdamez, 2017). Tais estratégias também foram selecionadas para o crescimento no ambiente doméstico e as ações de internacionalização das organizações (Fleury \& Fleury, 2012).

No tocante aos tipos de F\&A, elas podem ser horizontais - entre empresas do mesmo setor de atividade; verticais - entre uma organização e seu fornecedor ou cliente e podem ser relacionadas ou não quando as entidades envolvidas pertencem a setores em comum ou sem conexão direta; ou internacionais, 
o que constitui um dos principais modos de entrada em processos de internacionalização (Hitt et al., 2014; Haeruddin, 2017). Camargos e Barbosa (2005b) citam outras classificações das F\&A, no que diz respeito ao aspecto financeiro: as financeiras propriamente ditas; e as operacionais ou estratégicas, as quais possuem sinergia e, de maneira conjunta, geram maior rentabilidade do que separadas. Nestas últimas, de acordo com Carmona e Araújo (2011, p. 3), a união de duas organizações precisa "melhorar a produtividade, ou cortar custos, de modo que os fluxos de caixa não-alavancados da empresa combinada excedam aos fluxos de caixa não-alavancados combinados das empresas individuais", com vistas a obter sinergias operacionais. Em contrapartida, aquelas que não possuem sinergia são denominadas financeiras, em que "a empresa compradora normalmente acredita que o preço das ações da companhia é menor do que o valor dos ativos da mesma" (idem) - nesse caso, a principal motivação compreende os benefícios fiscais.

Segundo Zilber e Piekny (2005) e Hitt et al. (2014), os motivos mais comuns para a escolha de uma estratégia de F\&A são: ampliar market share (fatia de mercado); entrar em novos mercados ou ter acesso a novos canais de distribuição; obter novos produtos; exercer inovações e descobertas em produtos ou tecnologia para reduzir prazos e custos, além de melhorar a qualidade; diminuir o número de competidores; capitalizar em razão de mudanças na política e nas regras; fortalecer a reputação e a imagem; ou aumentar a credibilidade.

A estratégia de F\&A é um fator crucial para o desenvolvimento das organizações; porém, está condicionada a diferentes variáveis dos ambientes interno e externo que irão impactar tanto os antecedentes da decisão pelas F\&A quanto as escolhas sobre o processo de execução e análise dos resultados (Araújo, Goldner, Brandão, \& Oliveira, 2007; Welch et al., 2017; Khan et al., 2020). De acordo com Bettinazzi, Miller e Corbetta (2018), a maior parte da literatura sobre F\&A foca nos determinantes do sucesso das diferentes combinações organizacionais e dos resultados obtidos, com escassas pesquisas acerca dos direcionadores da seleção do alvo, como as características de similaridade entre as empresas e o quanto a proximidade pode influenciar nos resultados de F\&A. Khan et al. (2020) acrescentam que poucas investigações tratam de falhas e insucessos das estratégias de F\&A, apesar de estudos mostrarem altos índices de fracasso ao longo dos anos.

Em suma, as estratégias de F\&A são primordiais para o cenário econômico dos países e oferecem variadas possibilidades de estudo e análise, sob o ponto de vista do método e da gestão de negócios, como apontado por Shi et al. (2012) e por Reddy (2015).

\section{Procedimentos metodológicos}

Com o escopo de atender aos objetivos deste estudo, foi realizada a revisão de literatura composta pelas revisões bibliométrica e integrativa. Uma das vantagens do primeiro tipo de estudo diz respeito à observação do panorama de determinado domínio de conhecimento por meio de alguns indicadores quantitativos, com o auxílio de ferramentas estatísticas e análise de citações (Paul \& Criado, 2020). Esta 
última, conforme Vogel e Guttel (2013), pode ser mais descritiva ou avaliativa e contribui tanto para revelar a tradição intelectual de determinado campo quanto para desenvolvê-lo de fato.

Por seu turno, a revisão bibliométrica permite "computar dados para comparar e confrontar os elementos presentes em referências bibliográficas de documentos representativos das publicações" (Kobashi \& Santos, 2008, p. 109). Na análise da produção de um trabalho bibliométrico, são utilizadas três leis básicas de Bradford, Zipf e Lotka, conforme o Quadro 1.

Quadro 1 - Leis da pesquisa bibliométrica

\begin{tabular}{|l|l|l|l|}
\hline \multicolumn{1}{|c|}{ Leis } & \multicolumn{1}{c|}{ Medida } & \multicolumn{1}{c|}{ Critério } & \multicolumn{1}{c|}{ Objetivo Principal } \\
\hline $\begin{array}{l}\text { Lei de } \\
\text { Bradfort }\end{array}$ & $\begin{array}{l}\text { Grau de atração } \\
\text { do periódico }\end{array}$ & $\begin{array}{l}\text { Reputação do } \\
\text { periódico }\end{array}$ & $\begin{array}{l}\text { Identificar os periódicos mais relevantes e que } \\
\text { proporcionam maior vazão a um tema específico. }\end{array}$ \\
\hline Lei de Lotka & $\begin{array}{l}\text { Produtividade } \\
\text { do autor }\end{array}$ & $\begin{array}{l}\text { Tamanho da } \\
\text { frequência }\end{array}$ & $\begin{array}{l}\text { Levantar o impacto da produção de um autor em } \\
\text { determinada área do conhecimento. }\end{array}$ \\
\hline Lei de Zipf & $\begin{array}{l}\text { Frequência de } \\
\text { palavras-chave }\end{array}$ & $\begin{array}{l}\text { Lista ordenada } \\
\text { de temas }\end{array}$ & $\begin{array}{l}\text { Estimar os temas mais recorrentes relacionados a } \\
\text { um campo de conhecimento. }\end{array}$ \\
\hline
\end{tabular}

Fonte: Adaptado de Chueke e Amatucci (2015).

Muitas vezes, ao observar os resultados de uma revisão bibliométrica, um número relativamente pequeno de artigos representa a maior parte das citações analisadas sobre o tema (Paul \& Criado, 2020). Basicamente, há dois métodos baseados na verificação de citações, usados para mapear a literatura científica em um campo de estudo - as análises de cocitação e de acoplamento bibliográfico. Ambas apresentam relações intertextuais entre publicações científicas estabelecidas por meio do comportamento referencial dos autores, com pressuposto de que há alguma similaridade textual entre os documentos (Vogel \& Guttel, 2013; Grácio, 2016). Enquanto a análise de cocitação mensura a relação entre dois documentos, com base no número de publicações onde eles são citados de maneira concomitante, o acoplamento bibliográfico mede a relação entre dois documentos a partir da quantidade de referências comuns (Grácio, 2016).

Já a abordagem integrativa da revisão de literatura tem o propósito de avaliar, criticar e sintetizar o conteúdo da produção acadêmica de um determinado assunto, tópico ou campo do conhecimento, com vistas a não apenas sintetizá-la, mas também expandir e rever teorias existentes e estimular novas teorias e abordagens (Snyder, 2019). A revisão integrativa se atenta com menos frequência no tocante à estruturação rigorosa da coleta de dados do que sistemática, por exemplo, ao usar critérios mais amplos para seleção de materiais, pois a preocupação principal é propiciar uma visão integradora dos achados que levem a avanços teóricos, novos modelos de análise e diferentes perspectivas metodológicas (Torraco, 2005).

Sendo assim, este artigo consiste em uma revisão bibliométrica e integrativa de artigos sobre F\&A publicados em português e no Brasil, na área de gestão. Quanto à abordagem temporal, trata-se de um estudo longitudinal que realiza um levantamento das publicações relativas às F\&A no período de $2000 \mathrm{a}$ 2018. Na etapa inicial de coleta de dados, primeiramente, pesquisaram-se os artigos acadêmicos que possuíam as palavras-chave "fusão" e "aquisição" na plataforma Spell da Associação Nacional dos 
Programas de Pós-graduação em Administração (ANPAD), sendo encontradas apenas 12 publicações. Diante dessa pequena quantidade, os termos pesquisados se alteraram para "fusões" e "aquisições", que também foram utilizados na busca no Portal de Periódicos da Capes, o que resultou em 85 produções disponíveis nos dois portais. Por conseguinte, a amostra inicial foi composta por 97 artigos identificados pelas expressões “fusão", "aquisição", "fusões” e "aquisições".

Em seguida, realizou-se a leitura dos artigos coletados para fins de triagem, mais especificamente do resumo, da introdução e da conclusão, para selecionar as produções cujo tema de F\&A era foco do objetivo de pesquisa. Algumas investigações partiam das F\&A como um fator desencadeador do fenômeno a ser estudado, praticamente sem mencionar o conceito, as características e os demais elementos dessas estratégias no referencial teórico e na análise dos dados. Ao fim dessa etapa, restaram 68 artigos lidos posteriormente, com a respectiva organização dos dados em uma planilha do programa Microsoft Office Excel $^{\circledR}$.

Nesse entremeio, a organização dos dados auxiliou na revisão bibliométrica, com destaque para o ano de publicação, o título, a quantidade de autores, o objetivo, as palavras-chave, a instituição de ensino, o tipo de estudo a área de atuação - vale ressaltar que foram utilizadas as três leis fundamentais que regem as investigações bibliométricas. Com vistas a garantir a confiabilidade desse tipo de estudo, após a obtenção dos trabalhos a serem analisados, é fundamental descrever os parâmetros constitutivos da base de dados para categorizá-los e, posteriormente, aplicar as leis da bibliometria (Macias-Chalupa, 1998).

Em uma análise mais aprofundada e menos descritiva dos trabalhos selecionados, depois de elaborada e revisada a planilha, foram gerados arquivos no formato .csv por meio do software VOSviewer ${ }^{\circledR}$, para verificação da rede de palavras e temas (com informações sobre autores, títulos e resumos) e de cocitações (com dados sobre autores, títulos, periódico, ano e referências usadas em cada publicação). Devido à falta de padronização dos formatos dos artigos, não se analisou o acoplamento bibliográfico, pois não foi possível gerar uma base de dados completa e consistente para o uso de programas que geram mapas de acoplamento. Nesse caso, utilizaram-se os softwares Atlas $\mathrm{TI}^{\circledR}$ na identificação de agrupamentos temáticos (carregamento de todos os arquivos .pdf para o Atlas $\mathrm{TI}^{\circledR}$ ) e FreeMind ${ }^{\circledR}$ na visualização e estruturação das informações desses grupos.

De acordo com Torraco (2005), a revisão integrativa da literatura precisa da desconstrução do tema em conceitos principais que foram abordados; da visão histórica da evolução do tema; das relações entre os conceitos e entre eles e os métodos de pesquisa; e das aplicações no material examinado. Para isso, foram elencadas algumas perguntas norteadoras, como sugere Snyder (2019), que auxiliam na execução desse tipo de revisão: (i) quem é a audiência potencial do estudo?; (ii) quais informações são necessárias para examinar os caminhos teóricos percorridos pelos autores dos artigos?; (iii) quais informações são necessárias para fazer análises específicas de temas, métodos e contribuições?; (iv) quais as relações entre os artigos analisados?; e (v) É possível identificar agrupamentos de temas, autores ou instituições? 
A partir desses elementos, foi possível fazer a análise integrativa dos dados, com o intuito de dialogar entre diferentes agrupamentos temáticos, abordagens e vertentes teóricas e metodológicas encontradas nos trabalhos.

\section{Apresentação e discussão dos resultados}

Primeiramente, apresentam-se os achados resultantes da revisão bibliométrica e, em seguida, é destacada e comentada a síntese dos resultados, oriunda da revisão integrativa, com a discussão e o apontamento de lacunas e possíveis caminhos de pesquisa.

Na Figura 1 é mostrada a distribuição anual dos 68 artigos e o respectivo percentual desde 2000 somente nos anos 2000 e 2003, não foi encontrado nenhum artigo no período estudado. Observa-se que o tema, nas bases pesquisadas, não é abordado de forma linear e que há picos de elaborações em alguns anos, como 2005, 2010, 2013, 2015, 2016 e 2018. Apesar da não linearidade, foi notada uma tendência de crescimento em tais quantidades, cuja média de produção é de quatro artigos por ano.

Figura 1 - Quantidade de produções anuais e porcentagem do total

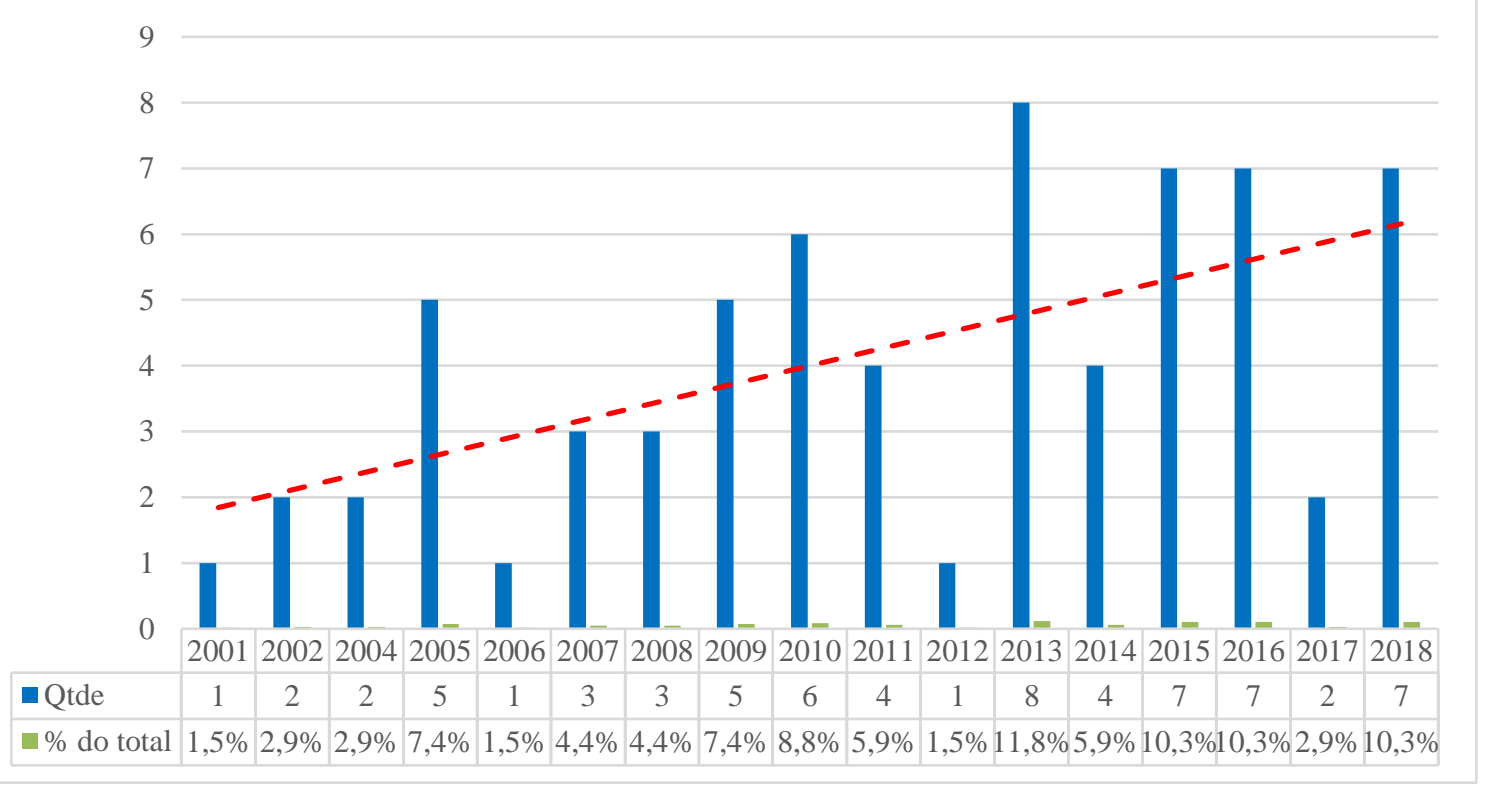

Fonte: Elaboração dos autores.

Na Tabela 1, constata-se que cinco anos (29\% do total do período analisado) foram responsáveis por mais de $50 \%$ da produção a respeito do tema. Esse recorte diz respeito aos anos mais recentes que apontam para um aumento consistente das produções a partir de 2010, o que eleva a média anual para 7 entre 2010 e 2018. 
Tabela 1 - Produção anual e acumulada

\begin{tabular}{c|c|c|c|c}
\hline $\mathbf{N}$. & Ano & Produção & \% de Produção & \% Acumulado \\
\hline $\mathbf{1}$ & $\mathbf{2 0 1 3}$ & $\mathbf{8}$ & $\mathbf{1 1 , 8 \%}$ & $\mathbf{1 1 , 8 \%}$ \\
$\mathbf{2}$ & $\mathbf{2 0 1 5}$ & $\mathbf{7}$ & $\mathbf{1 0 , 3 \%}$ & $\mathbf{2 2 , 1 \%}$ \\
$\mathbf{3}$ & $\mathbf{2 0 1 6}$ & $\mathbf{7}$ & $\mathbf{1 0 , 3 \%}$ & $\mathbf{3 2 , 4 \%}$ \\
$\mathbf{4}$ & $\mathbf{2 0 1 8}$ & $\mathbf{7}$ & $\mathbf{1 0 , 3 \%}$ & $\mathbf{4 2 , 7 \%}$ \\
$\mathbf{5}$ & $\mathbf{2 0 1 0}$ & $\mathbf{6}$ & $\mathbf{8 , 8 \%}$ & $\mathbf{5 1 , 5 \%}$ \\
6 & 2009 & 5 & $7,4 \%$ & $58,9 \%$ \\
7 & 2005 & 5 & $7,4 \%$ & $66,3 \%$ \\
8 & 2011 & 4 & $5,9 \%$ & $72,2 \%$ \\
9 & 2014 & 4 & $5,9 \%$ & $78,1 \%$ \\
10 & 2007 & 3 & $4,4 \%$ & $82,5 \%$ \\
11 & 2008 & 3 & $4,4 \%$ & $86,9 \%$ \\
12 & 2002 & 2 & $2,9 \%$ & $89,8 \%$ \\
13 & 2004 & 2 & $2,9 \%$ & $92,7 \%$ \\
14 & 2017 & 2 & $2,9 \%$ & $95,6 \%$ \\
15 & 2001 & 1 & $1,5 \%$ & $97,1 \%$ \\
16 & 2006 & 1 & $1,5 \%$ & $98,6 \%$ \\
17 & 2012 & 1 & $1,5 \%$ & $100 \%$ \\
18 & 2000 & 0 & - & - \\
19 & 2003 & 0 & - & - \\
\hline
\end{tabular}

Fonte: Elaboração dos autores.

A Figura 2 ilustra a distribuição do número de autores por publicação, em que 37 artigos (54\% da amostra) foram elaborados por dois pesquisadores, e a soma de publicações de dois autores com as de três investigadores é de $81 \%$. A produção conjunta entre dois autores pode ser oriunda de dissertações e teses (aluno que publica juntamente com o orientador), enquanto os trabalhos de três ou mais autores podem indicar a existência de grupos de pesquisa ou de interesse pelo tema.

Figura 2 - Frequência de autores por publicação

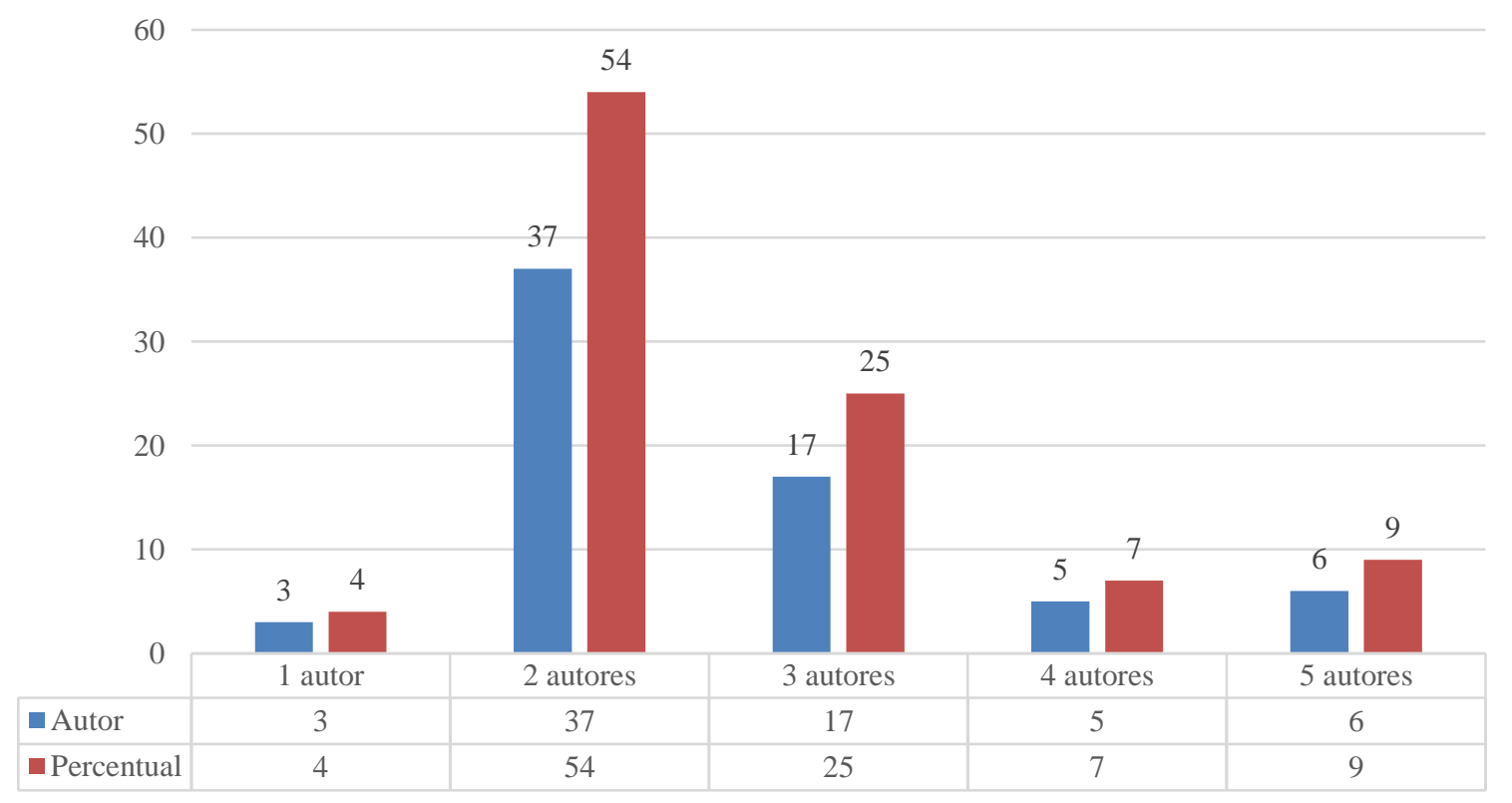

Fonte: Elaboração dos autores. 
Conforme a Tabela 2, os 68 artigos analisados foram publicados em 39 periódicos diferentes, em que 16 deles tiveram mais de uma publicação sobre o tema. Ao aplicar a lei da bibliometria de Bradford, notou-se a concentração de produções em algumas revistas, enquanto muitos deles apresentam apenas um trabalho no período. O periódico que mais divulgou estudos sobre F\&A foi a Revista de Gestão (REGE), com seis artigos, seguida pela Revista de Administração Contemporânea (RAC), com cinco, e pela Contextus - Revista Contemporânea de Economia e Gestão, com quatro elaborações. Assim, sete dos 39 periódicos publicaram em torno de $40 \%$ do total de produções sobre o tema (de três a seis artigos cada), e os 16 veículos de divulgação com mais de um artigo foram responsáveis por $67 \%$ das publicações no recorte analisado.

Tabela 2 - Publicações por ano nos periódicos

\begin{tabular}{|c|c|c|c|c|c|}
\hline N. & Periódico & Qtde. & $\%$ & \% Total & Período \\
\hline $\mathbf{1}$ & Revista de Gestão (REGE) & 6 & $9 \%$ & $9 \%$ & $\begin{array}{c}2005(2), 2008,2010, \\
2015,2016\end{array}$ \\
\hline 2 & Revista de Administração Contemporânea (RAC) & 5 & $7 \%$ & $16 \%$ & $\begin{array}{l}2001,2005,2009 \\
2013,2015\end{array}$ \\
\hline 3 & $\begin{array}{l}\text { Contextus - Revista Contemporânea de Economia } \\
\text { e Gestão }\end{array}$ & 4 & $6 \%$ & $22 \%$ & $\begin{array}{l}2007,2010,2015, \\
2016\end{array}$ \\
\hline 4 & Contabilidade, Gestão e Governança & 3 & $4 \%$ & $26 \%$ & $2014,2018(2)$ \\
\hline 5 & Revista Administração em Diálogo & 3 & $4 \%$ & $30 \%$ & 2002, 2010, 2014 \\
\hline 6 & Revista de Ciências da Administração & 3 & $4 \%$ & $34 \%$ & 2010, 2016, 2018 \\
\hline 7 & Revista de Finanças Aplicadas & 3 & $4 \%$ & $40 \%$ & 2013, 2014, 2018 \\
\hline 8 & Contabilidade Vista e Revista & 2 & $3 \%$ & $43 \%$ & 2009,2016 \\
\hline 9 & Revista de Administração & 2 & $3 \%$ & $46 \%$ & 2004,2006 \\
\hline 10 & Revista de Administração de Empresas & 2 & $3 \%$ & $49 \%$ & 2005,2008 \\
\hline 11 & Revista de Administração FACES Journal & 2 & $3 \%$ & $52 \%$ & 2013, 2014 \\
\hline 12 & Revista de Administração Mackenzie & 2 & $3 \%$ & $55 \%$ & 2002, 2012 \\
\hline 13 & Revista Economia \& Gestão & 2 & $3 \%$ & $58 \%$ & 2004, 2010 \\
\hline 14 & Revista Eletrônica de Estratégia \& Negócios & 2 & $3 \%$ & $61 \%$ & 2011,2010 \\
\hline 15 & Revista Gestão \& Tecnologia & 2 & $3 \%$ & $64 \%$ & 2009, 2018 \\
\hline 16 & $\begin{array}{l}\text { Revista Pensamento Contemporâneo em } \\
\text { Administração }\end{array}$ & 2 & $3 \%$ & $67 \%$ & 2013, 2015 \\
\hline
\end{tabular}

Fonte: Elaboração dos autores.

De 140 autores, apenas 21 publicaram mais de um artigo. Na Tabela 3, estão listados os sete estudiosos com produção maior ou superior a duas publicações, a Instituição de Ensino Superior (IES), a quantidade de artigos realizados, o percentual de trabalhos perante o total de elaborações e os respectivos períodos. Verificou-se que dois autores - Marcos Antônio de Camargos, da Universidade Federal de Minas Gerais (UFMG), com nove artigos e Francisco Vidal Barbosa, também da UFMG, com sete - se destacam com o maior número de produções, ao se sobressaírem como autores em 13\% e 10\% dos artigos, respectivamente. Outros cinco pesquisadores aparecem como autores de cinco artigos cada, o que corresponde a $20 \%$ da produção total; logo, em $43 \%$ do total de publicações de 2000 a 2018 , sete investigadores listados abaixo aparecem como autores ou coautores. 
Tabela 3 - Produção por autor

\begin{tabular}{clcccc}
\hline N. & \multicolumn{1}{c}{ Autores } & IES & $\begin{array}{c}\text { Número de }^{\text {artigos }}{ }^{1} \\
\text { a do }^{2}\end{array}$ & $\begin{array}{c}\% \\
\text { total }\end{array}$ & Ano \\
\hline 1 & Marcos Antônio de Camargos & UFMG & 9 & $13 \%$ & $\begin{array}{c}2005(3), 2006,2007, \\
2008(2), 2009,2011\end{array}$ \\
& & & & & $2005(3), 2006,2008$ \\
2 & Francisco Vidal Barbosa & UFMG & 7 & $10 \%$ & $(2), 2009$ \\
3 & Aldo Leonardo Cunha Callado & UFPB & 3 & $4 \%$ & $2015,2016(2)$ \\
4 & Cristina Lelis Leal Calegario & UFLA & 3 & $4 \%$ & $2012,2014,2018$ \\
5 & Leandro Augusto Toigo & UNIOESTE & 3 & $4 \%$ & $2017,2018(2)$ \\
6 & Moisés Ari Zilber & USP/Mackenzie & 3 & $4 \%$ & $2002(2), 2011$ \\
7 & Nelson Hein & FURB & 3 & $4 \%$ & $2017,2018(2)$ \\
\hline
\end{tabular}

${ }^{1}$ Inclui a produção conjunta/coautoria.

Fonte: Elaboração dos autores.

Dentre os sete autores supramencionados, não há produções continuadas no período de 2011 a 2018: Marcos Antônio de Camargos e Francisco Vidal Barbosa possuem publicações conjuntas (2005, 2006 e 2009); Moisés Ari Zilber elaborou dois artigos em 2002 e voltou ao tema em 2011; Aldo Leonardo Cunha Callado publicou em 2015 e 2016; e Cristina Lelis Leal Calegario, Leandro Augusto Toigo e Nelson Hein têm artigos em anos mais recentes. Mesmo sem uma produção continuada entre os autores que mais publicaram, ao aplicar a Lei de Lotka, verificou-se a concentração entre poucos pesquisadores no período, enquanto muitos deles publicaram apenas uma vez nos anos investigados.

$\mathrm{Na}$ Tabela 4, são apresentadas as produções por IES, em que 42 universidades se relacionaram aos 68 textos analisados. Destas, a instituição com maior número de artigos (pelo menos um dos autores estava ligado a ela no momento da publicação) foi a UFMG, com 16 trabalhos, seguida pela Universidade de São Paulo (USP), com cinco. Ademais, cinco instituições apareceram em quatro artigos: Universidade Regional de Blumenau (FURB), Pontifícia Universidade Católica de São Paulo (PUC-SP), Universidade Federal de Lavras (UFLA), Universidade Federal de Santa Catarina (UFSC) e Universidade Nove de Julho (UNINOVE). Vale ressaltar que, em 46 artigos (68\% do total), todos os autores estavam vinculados à mesma instituição; portanto, somente 22 produções (ou $32 \%$ do total) foram feitas em coautoria interinstitucional.

Tabela 4 - Artigos produzidos por IES

\begin{tabular}{cc|c}
\hline N. & Instituição de Ensino Superior & Quantidade de artigos \\
\hline $\mathbf{1}$ & Universidade Federal de Minas Gerais (UFMG) & $\mathbf{1 6}$ \\
$\mathbf{2}$ & Universidade de São Paulo (USP) & 4 \\
3 & Universidade Regional de Blumenau (FURB) & 4 \\
4 & Pontifícia Universidade Católica de São Paulo (PUC-SP) & 4 \\
5 & Universidade Federal de Lavras (UFLA) & 4 \\
6 & Universidade Federal de Santa Catarina (UFSC) & 4 \\
7 & Universidade Nove de Julho (UNINOVE) & 3 \\
8 & Universidade Federal da Paraíba (UFPB) & 3 \\
9 & Universidade de Fortaleza (UNIFOR) & 3 \\
10 & Universidade Estadual do Oeste do Paraná (UNIOESTE) & 3 \\
11 & Universidade Presbiteriana Mackenzie (UPM) & \\
\hline
\end{tabular}

Fonte: Elaboração dos autores. 
De fato, a maior parte da produção foi elaborada com a participação de autores da mesma instituição, mas há vários trabalhos resultantes de parcerias institucionais. Essas parcerias se caracterizam por proximidade geográfica, seja entre as instituições do Sul do Brasil - UFSC, Universidade Federal do Rio Grande do Sul (UFRGS), Furb e Unioeste; e as do Sudeste, com a concentração de estudos oriundos de instituições paulistas - USP, Mackenzie, Uninove, PUC-SP, Universidade Estadual de Campinas (UNICAMP) e Faculdades Metropolitanas Unidas (FMU) e mineiras - UFMG, UFLA, Fundação Dom Cabral (FDC), Pontifícia Universidade Católica de Minas Gerais (PUC-MG), Universidade Federal de Juiz de Fora (UFJF) e Centro Universitário UNA.

Já sobre os objetivos dos estudos, na Tabela 5, o verbo mais recorrente foi "analisar" e, em segundo lugar, "identificar" - tais expressões foram seguidas de forma mais distante por "avaliar" e "verificar" o fato/fenômeno/processo da F\&A, fatores e elementos relacionados, bem como desdobramentos e resultados. Em 2010, 2013, 2015 e 2016, os objetivos foram mais diversificados, o que sugere que, nesses períodos, houve expansão do campo de pesquisa.

Tabela 5 - Objetivo por ano de publicação

\begin{tabular}{|c|c|c|c|c|c|c|c|c|c|c|c|c|c|c|c|c|c|c|}
\hline \multirow{5}{*}{ Objetivo } & \multicolumn{17}{|c|}{ Ano } & \multirow{5}{*}{ Total } \\
\hline & 2 & 2 & 2 & 2 & 2 & 2 & 2 & 2 & 2 & 2 & 2 & 2 & 2 & 2 & 2 & 2 & 2 & \\
\hline & 0 & 0 & 0 & 0 & 0 & 0 & 0 & 0 & 0 & 0 & 0 & $\mathbf{0}$ & 0 & $\mathbf{0}$ & $\mathbf{0}$ & 0 & 0 & \\
\hline & 0 & 0 & 0 & 0 & 0 & 0 & 0 & 0 & 1 & 1 & 1 & 1 & 1 & 1 & 1 & 1 & 1 & \\
\hline & 1 & 2 & 4 & 5 & 6 & 7 & 8 & 9 & 0 & 1 & 2 & 3 & 4 & 5 & 6 & 7 & 8 & \\
\hline Abordar & 0 & 0 & 0 & 1 & 0 & 0 & 0 & 0 & 0 & 0 & 0 & 1 & 0 & 0 & 0 & 0 & 0 & 2 \\
\hline Analisar & 1 & 0 & 1 & 1 & 1 & 2 & $\mathbf{0}$ & $\mathbf{0}$ & 3 & 2 & 0 & 2 & $\mathbf{0}$ & 3 & 4 & $\mathbf{0}$ & 3 & 23 \\
\hline Apresentar & 0 & 0 & 0 & 0 & 0 & 0 & 0 & 0 & 1 & 0 & 0 & 0 & 0 & 0 & 0 & 0 & 1 & 2 \\
\hline Avaliar & 0 & 0 & $\mathbf{0}$ & 1 & 1 & 0 & 1 & 1 & 1 & 0 & 0 & 1 & $\mathbf{0}$ & 1 & $\mathbf{0}$ & $\mathbf{0}$ & $\mathbf{0}$ & 7 \\
\hline Caracterizar & 0 & 0 & 0 & 0 & 0 & 0 & 0 & 0 & 0 & 0 & 0 & 0 & 0 & 0 & 2 & 0 & 0 & 2 \\
\hline Compreender & 0 & 0 & 0 & 0 & 0 & 0 & 0 & 0 & 0 & 1 & 0 & 0 & 0 & 0 & 0 & 0 & 0 & 1 \\
\hline Conhecer & 0 & 0 & 0 & 0 & 0 & 0 & 0 & 0 & 0 & 0 & 0 & 0 & 0 & 1 & 0 & 0 & 0 & 1 \\
\hline Constatar & 0 & 0 & 0 & 0 & 0 & 1 & 0 & 0 & 0 & 0 & 0 & 0 & 0 & 0 & 0 & 0 & 0 & 1 \\
\hline Contextualizar & 0 & 0 & 0 & 0 & 0 & 1 & 0 & 0 & 0 & 0 & 0 & 0 & 0 & 0 & 0 & 0 & 0 & 1 \\
\hline Descrever & 0 & 0 & 0 & 0 & 0 & 1 & 0 & 0 & 0 & 0 & 0 & 0 & 0 & 1 & 0 & 0 & 0 & 2 \\
\hline Discutir & 0 & 0 & 1 & 1 & 0 & 0 & 0 & 0 & 0 & 0 & 0 & 0 & 0 & 0 & 0 & 0 & 0 & 2 \\
\hline Entender & 0 & 0 & 0 & 0 & 0 & 1 & 0 & 0 & 0 & 0 & 0 & 2 & 0 & 0 & 0 & 0 & 0 & 3 \\
\hline Identificar & 0 & 2 & $\mathbf{0}$ & 0 & $\mathbf{0}$ & $\mathbf{0}$ & 2 & 2 & 2 & 1 & 0 & 2 & 1 & 1 & 3 & 1 & 2 & 19 \\
\hline Investigar & 0 & 0 & 0 & 0 & 0 & 0 & 0 & 0 & 0 & 0 & 1 & 0 & 2 & 0 & 0 & 0 & 1 & 4 \\
\hline Levantar & 0 & 0 & 0 & 0 & 0 & 0 & 0 & 0 & 1 & 0 & 0 & 0 & 0 & 0 & 0 & 0 & 0 & 1 \\
\hline Relacionar & 0 & 0 & 0 & 1 & 0 & 0 & 0 & 0 & 0 & 0 & 0 & 0 & 0 & 1 & 0 & 0 & 0 & 2 \\
\hline Verificar & 0 & $\mathbf{0}$ & 0 & 1 & 0 & 0 & $\mathbf{0}$ & 2 & 1 & 1 & 0 & $\mathbf{0}$ & 1 & $\mathbf{0}$ & $\mathbf{0}$ & 1 & $\mathbf{0}$ & 7 \\
\hline
\end{tabular}

Fonte: Elaboração dos autores.

Para iniciar o processo de identificação e análise de temas, foi elaborada uma word cloud (nuvem de palavras) a partir das palavras-chaves declaradas nos artigos. Para fins de análise, foram retiradas as expressões "fusão", "aquisição" e os respectivos sinônimos, com foco em mil vocábulos (Figura 3). 
Figura 3 - Word cloud com as palavras-chaves

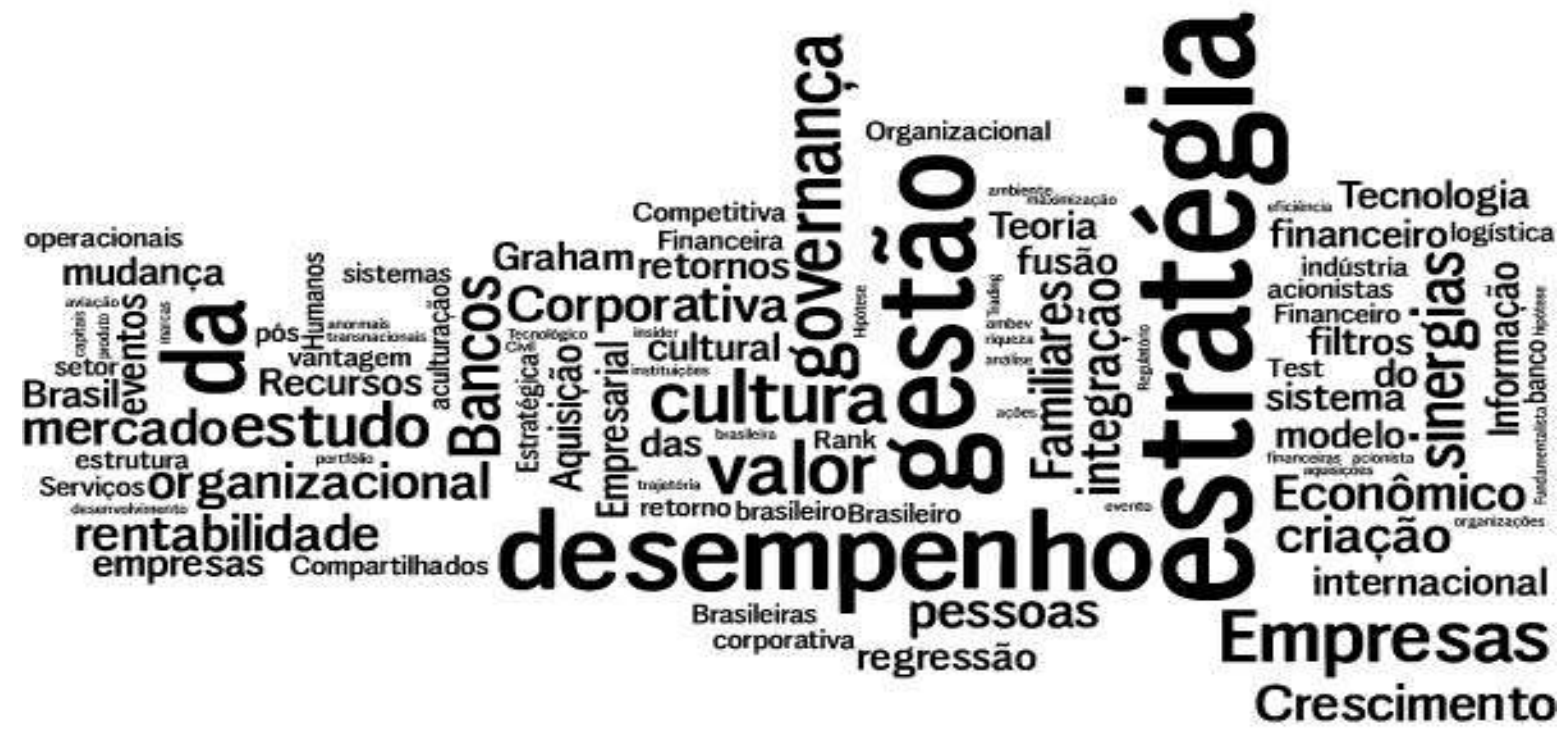

Fonte: Elaboração dos autores.

$\mathrm{Na}$ frequência das palavras-chaves, confirmou-se a Lei de Zipf, na qual, ao longo do tempo, é empregado um número reduzido de expressões que sintetizam o tema, com destaque para elementos como estratégia, desempenho, gestão, cultura, aspecto econômico, integração e crescimento.

Todavia, as evidências advindas somente das palavras-chaves escolhidas pelos autores não são suficentes para compreender e ilustrar o panorama de pesquisas da área de Administração sobre F\&A no Brasil, escritas em língua portuguesa. Então, com o auxílio do software VOSviewer ${ }^{\circledR}$, foram criados mapas que destacam e relacionam os termos mais citados nos títulos e resumos dos artigos analisados, além da densidade da relação entre eles. Partiu-se do número mínimo de cinco ocorrências por vocábulo, que resultaram na rede de palavras constante na Figura 4: 
Figura 4 - Rede de palavras - títulos e resumos

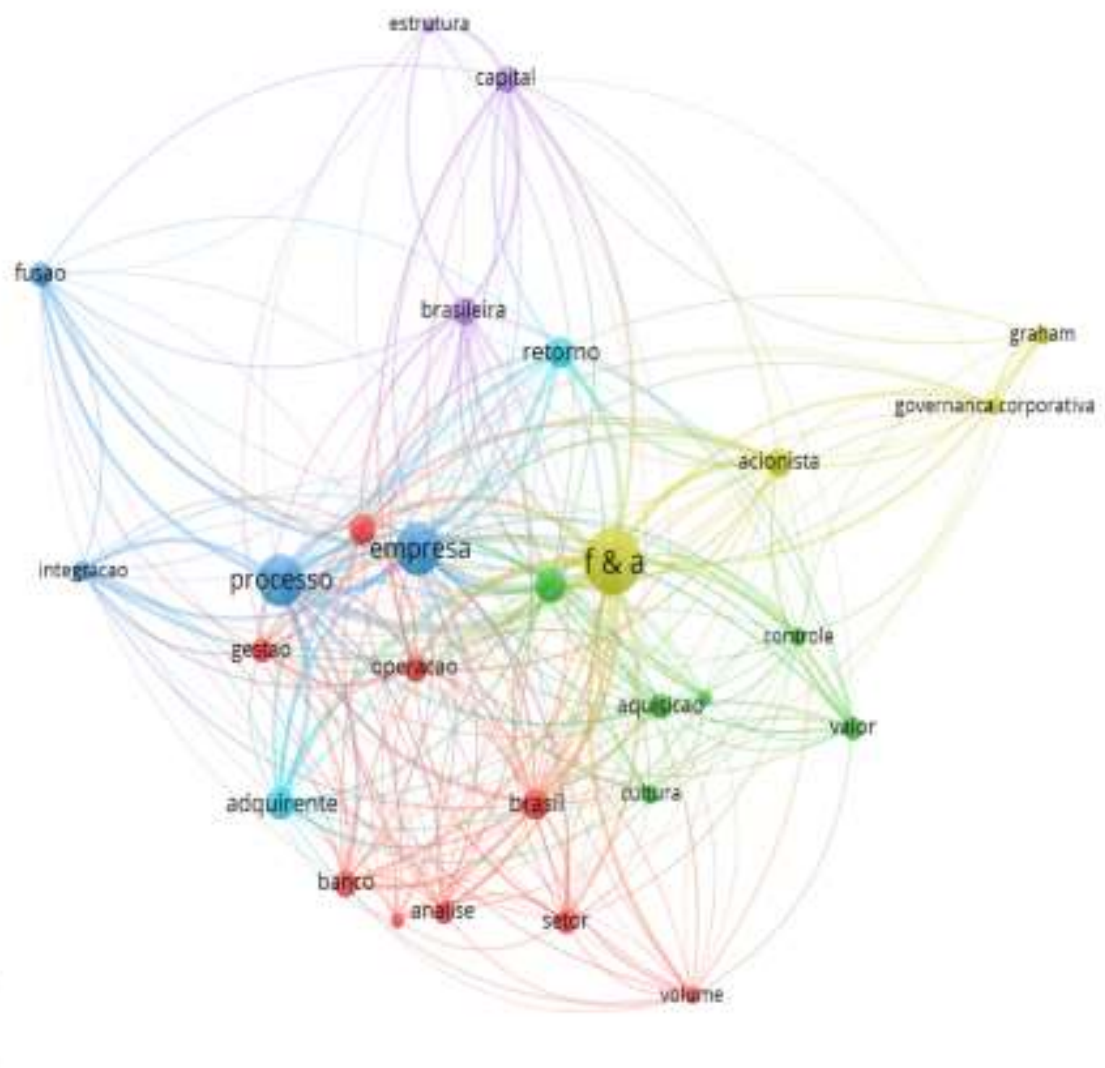

Fonte: Elaboração dos autores.

Conforme a Figura 4, a palavra "fusão", citada de forma isolada, está mais relacionada às questões sobre "integração", "processo" e "empresa", ao passo que o termo "aquisição" é fortemente ligado aos vocábulos "estratégia", "controle", "valor" e "estrutura". A expressão composta "F\&A” é o nó principal e está ligada aos outros termos, com mais densidade a "acionista" e "governança corporativa", além do filtro de "Graham" - este último é uma medida de avaliação de desempenho financeiro. De forma mais isolada, os termos "estrutura", "capital" e "brasileira" aparecem com grau mais elevado de relacionamento entre si e próximos a "retorno". Entre os vocábulos isolados "aquisição" e "fusão" aparece uma gama de termos mais densamente relacionados entre si e centralizados por "mercado", como "gestão", "operação", "análise", "volume", "setor", "banco" e "Brasil”.

Por meio dessa visualização, começaram a surgir as evidências de agrupamentos temáticos. No próximo passo, realizou-se a análise temática com o software Atlas $\mathrm{TI}^{\circledR}$, segundo os grupos de termos recorrentes ao longo do conteúdo dos artigos, a saber: Economia/Finanças, Estratégia, Gestão do Processo de F\&A e Aspectos Culturais.

Na Figura 5 é apresentado o total de artigos relacionados a cada agrupamento temático: 
Figura 5 - Artigos por agrupamento temático

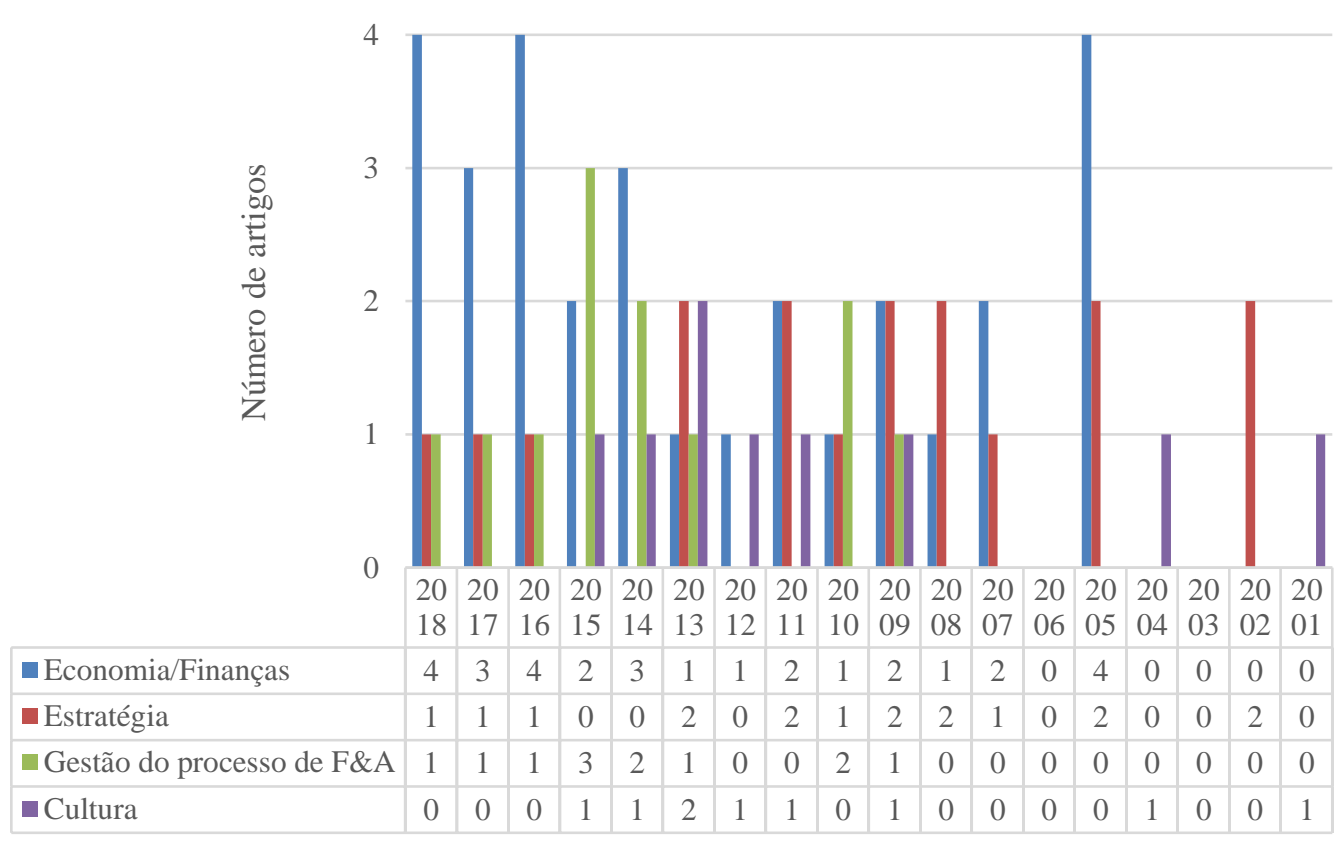

Fonte: Elaboração dos autores.

De acordo com a Figura 5, há a predominância de dois agrupamentos temáticos (Economia/Finanças e Estratégia) que apresentaram, ao menos, uma produção por ano. Economia/Finanças teve, em 2005, 2016 e 2018, quatro artigos em cada período; porém, tais trabalhos não se relacionam a nenhum fenômeno que pode ser claramente identificado no campo de F\&A, como o incremento no número de F\&A que envolveram expressivas somas de valores ou outro aspecto que, ao ser evidenciado, justifica os aumentos da produção. Já no que concerne à Estratégia, esse tema é recorrente e possui estreita relação com a dinâmica dos acontecimentos de mercado, mais especificamente de F\&A.

Para auxiliar na visualização da Figura 6, que mostra os agrupamentos temáticos, foi usado o software FreeMind ${ }^{\circledR}$ : 
Figura 6 - Agrupamento temático de F\&A

Toigo, L. A., Hein, N. \& Kroenke, A. (2018) Toigo, L. A, Hein, N., \& Wrubel, F. (2018) Santos, T. A. dos, Calegario, C. L. L., \& Carvatho, F. D. M. (2018) Viglioni, M. T. D., Carvatho, F. de M., Benedicto, G. C. de, \& Prado, J W. do. (2018)

Oliveirs, R. M. De, \& Pimenta, D. P. (2017) Vieira, L. B., Brito, S. S., Santana, J. R. B., Sanches, S. L. R., \& Galdamez, E. V.C. (2017)

Toigo, L. A. \& Hein, N. (2017) to Macohon, E. R.,Zittei, M. V. M., \&\& Klarn, R. C. (2010 Bomfim, E. T. do, \& Callado, A. L. C. (2016) Cardoso, A. A. B., \& Curi, M. A. (2016) Bomfim, E. T. do \& Callado, A. L. C. (2016)a Forric T S V S Caildo, A D C (2015) Romano, P. R, \& Almeida, V. de S.e. (2015) Pessanha, G. R. G., Santos, T. A, Calegário, C. L. L., Sáfadi, T., \& Alcântra, J.N. (2014)

Pimenta, D. P., \& Gartner, I. R (2014) Krieck, P. A., \& Kayo, B. K. (2014) Motta, L. F. J. da, Oliveira, P. V. C., Cavazzote, F. de S. C.N. \& Pinto, A C.F.C.F. (2013)

Pessanha, G. R. G., Calegario, C. L. L, Siafadi, T, \& Aizara, L.N. de. (2012)

Narsumoto. G. U., Ribeiro, K. C. S. \& Ferreira, L. G. (2011) Bichara, K. R. \& Camargos, M. A. (2011) Mota, M. de O., \& Ogasavara, M. H. (2011) Camargos, M. A, \& Barbosa, F. V, , (2010)e es के के है। Nello, R. C. (2009)

Camargos, M. A., \& Barbosa, F. V., (2009)d हो है। Camargos, M. A. de, Romero, J. A. R. \& Barbosa, F. V., (2008) Aráijo, C. A. G. da, Goldner, F., Brandào, M. M. \& Oliveira, F. R. (2007) Camargos, M. A.. \& Barbosa, F. V., (2007) C F Brito, G. A. S., Bacistella. F. D. \& Famá R. (2005) Camargos, M. A. \& Barbosa, F. V., (2005) (6) Camargos, M. A., \& Barbosa, F. V., (2005)a eo Camargos, M. A., \& Barbosa, F. V., (2005)b

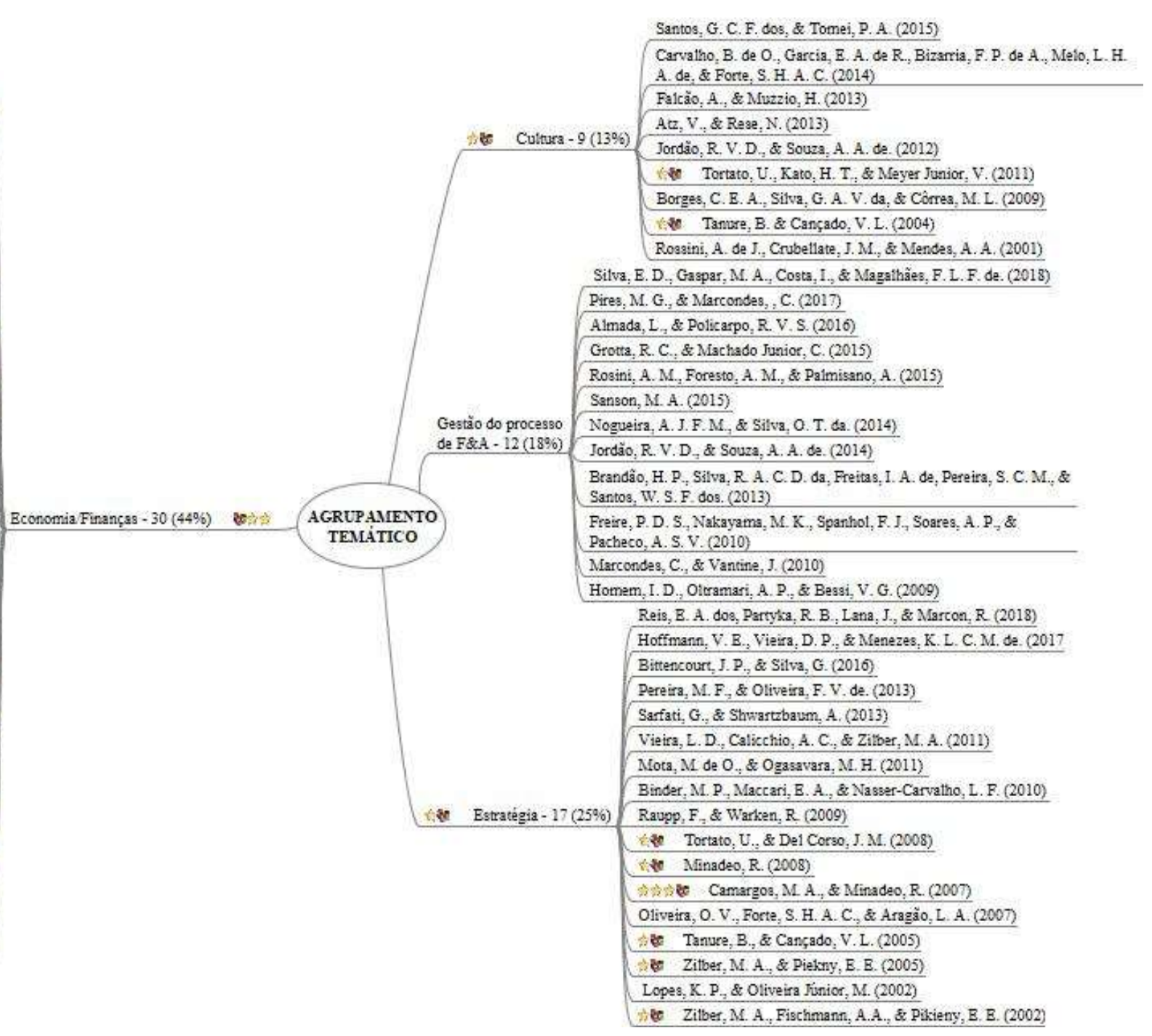

Fonte: Elaboração dos autores.

Rev. Ibero-Am. de Est. - RIAE Iberoamerican Journal of Strategic Management - IJSM São Paulo, 19(4), p. 76-99, Oct./Dec. 2020 
Quanto à distribuição dos trabalhos no agrupamento temático Economia/Finanças, os pesquisadores com maior número de artigos foram Marcos Antônio de Camargos e Francisco Vidal Barbosa, com cinco publicações em 2005 (duas), 2007 (uma), 2009 (uma) e 2010 (uma); em outras parcerias, esses autores elaboraram uma pesquisa com Júlio Alfredo Racchumi Romero, em 2008, e outra com Kelma Rodrigues Bichara, em 2011. Tanto Marcos quanto Francisco, depois de 2011, não publicaram outros estudos, seja individualmente ou com outros pesquisadores. Vale registrar a produção de Leandro Toigo e Nelson Hein em 2017, além das coautorias com Adriana Kroenke e Franciele Wrubel em 2018, com uma publicação cada. Consideram-se, ainda, Emanoel Truta do Bomfim e Aldo Leonardo Cunha Callado, com dois artigos em 2016, e uma produção de Talieh S. V. Ferreira e Aldo Leonardo Cunha Callado, em 2015.

O agrupamento temático Economia/Finanças é constituído por artigos que abordam o desempenho econômico financeiro, tema mais recorrente em Araújo et al. (2007) e Bomfim e Callado (2016); o desenvolvimento de sinergias em organizações brasileiras que passaram pelo processo de F\&A; a criação de valor para os acionistas (Camargos \& Barbosa, 2005a); as avaliações da receptividade do mercado e rentabilidade das ações de companhias que passaram pelo processo (como Vieira et al., 2017); a verificação de aspectos relativos a estratégias econômico-financeiras; e a análise da estrutura de capital de empresas (como e Viglione, Carvalho, Benedicto, \& Prado, 2018). Outros trabalhos relataram sobre as F\&A em empresas do mercado financeiro (Araújo et al., 2007) e de ações (Bichara \& Camargos, 2011) e os respectivos efeitos. O volume de F\&A e os efeitos no mercado de capitais e bancário também são estudados (Ferreira \& Callado, 2015). Em artigos mais recentes, surgem os temas sobre a teoria de agência e governança corporativa (como visto em Toigo, Hein, \& Kroenke, 2018). Várias pesquisas foram realizadas acerca da abordagem quantitativa, com uso de bases de dados como Economática, ao passo que outras investigações qualitativas adotaram estudos de casos de F\&A de maior notoriedade.

Em se tratando do agrupamento temático Estratégia existe uma produção diluída que não ultrapassa duas publicações por autor, como Moisés Ari Zilber e Eugen Erich Pikieny, em 2005 e Moisés Ari Zilber, Adalberto Américo Fischmann, A.A. e Eugen Erich Pikieny, em 2002.

$\mathrm{O}$ agrupamento temático Estratégia contempla estudos que tratam de resultados das F\&A voltados ao crescimento das organizações, à criação de vantagens competitivas (como em Pereira \& Oliveira, 2013), à expansão de plataformas de produtos (Zilber \& Piekny, 2005), a como as empresas adquirentes tratam as estratégias de marcas (Lopes \& Oliveira Júnior, 2002), à importância da escolha da estratégia da integração na motivação de F\&A, à influência das culturas organizacional e brasileira (Tanure \& Cançado, 2005) e às relações das F\&A com o processo sucessório (Atz \& Rese, 2013). Discorreu-se também sobre as alterações das estruturas organizacionais, o aumento da complexidade das empresas resultantes, o desenvolvimento de competências e de sinergia (como em Hoffmann, Vieira, \& Menezes, 2017), as mudanças resultantes nos setores de atividades, as cadeias produtivas e o desenvolvimento do país (como em Vieira, Callichio, \& Zilber, 2011). Foram investigadas algumas ferramentas para o auxílio nas decisões de F\&A (por 
exemplo, Raupp \& Warken, 2009, sobre due dilligence) e apenas uma pesquisa evidenciou a situação em que não foram alcançados os resultados esperados com a estratégia de F\&A (Binder et al., 2010). Na maior parte das investigações, os autores adotaram abordagem qualitativa com o estudo de caso único como método de pesquisa.

Quanto ao agrupamento temático Gestão do Processo de F\&A, a distribuição não passou de um artigo por autor - as produções foram iniciadas em 2009, com o máximo de três produções em 2015. Nesse grupo, identificaram-se trabalhos que discutiram as mudanças na área de gestão de pessoas como resultado do processo de F\&A (Nogueira \& Silva, 2014) e a importância da área para esse tipo de estratégia (como Brandão, Silva, Freitas, Pereira, \& Santos, 2013). A integração foi um tema recorrente com diferentes recortes, como a análise do impacto da emoção no processo de integração (Marcondes \& Vantine, 2010), bem como as causas de problemas e soluções de integração de pessoas, tecnologia e conhecimento (por exemplo, Pires \& Marcondes, 2017). Poucas investigações tratam de aspectos de liderança e mudança organizacional (como Almada \& Policarpo, 2016), assim como as mudanças no sistema de gestão, controle e indicadores de resultados não financeiros sobre F\&A (como em Jordão \& Souza, 2013). Praticamente todos os trabalhos são de abordagem qualitativa, em que se sobressai o estudo de caso único como método empregado na pesquisa de campo.

O agrupamento temático Cultura teve frequência de, no máximo, dois artigos por ano, sendo que, desde 2015, não foi identificado nenhum texto sobre o tema. É composto por trabalhos com foco em elementos culturais no processo de F\&A em contextos específicos, como em empresas de gestão familiar, cooperativas e bancos (a exemplo de Borges, Silva, \& Corrêa, 2009). Alguns estudos versaram sobre a mudança e a integração cultural tanto na perspectiva da organização adquirida como na adquirente (Carvalho, Garcia, Bizarria, Melo, \& Forte, 2014) ou em fusões entre entidades que eram concorrentes anteriormente (Falcão \& Muzzio, 2013). Também comporta investigações de diferentes perspectivas sobre os benefícios esperados e efetivamente adquiridos com a F\&A (Jordão \& Souza, 2012) e de reações de aceitação e resistência ao processo. As pesquisas, em sua maioria, possuem abordagem qualitativa, com uso do estudo de caso.

A interdisciplinaridade entre as investigações e os pesquisadores é ratificada nos agrupamentos temáticos, com elementos de complementariedade apontados na Figura 4, em se tratando da rede de palavras a partir de títulos e resumos. Esse fenômeno está presente em Cultura e Estratégia, nos quais Tortato (2008; 2011) e Tanure e Cançado (2004; 2005) tiveram publicações em ambos; e no agrupamento Economia/Finanças e Estratégia, foi encontrada a obra de Camargos e Minadeo (2007).

Para complementar a análise temática, elaborou-se o mapa de cocitação apresentado na Figura 7. São agrupados os autores mais citados nos trabalhos analisados, em consonância ao parâmetro de cinco citações por referência, pelo menos. 
Figura 7 - Rede de cocitação de autores

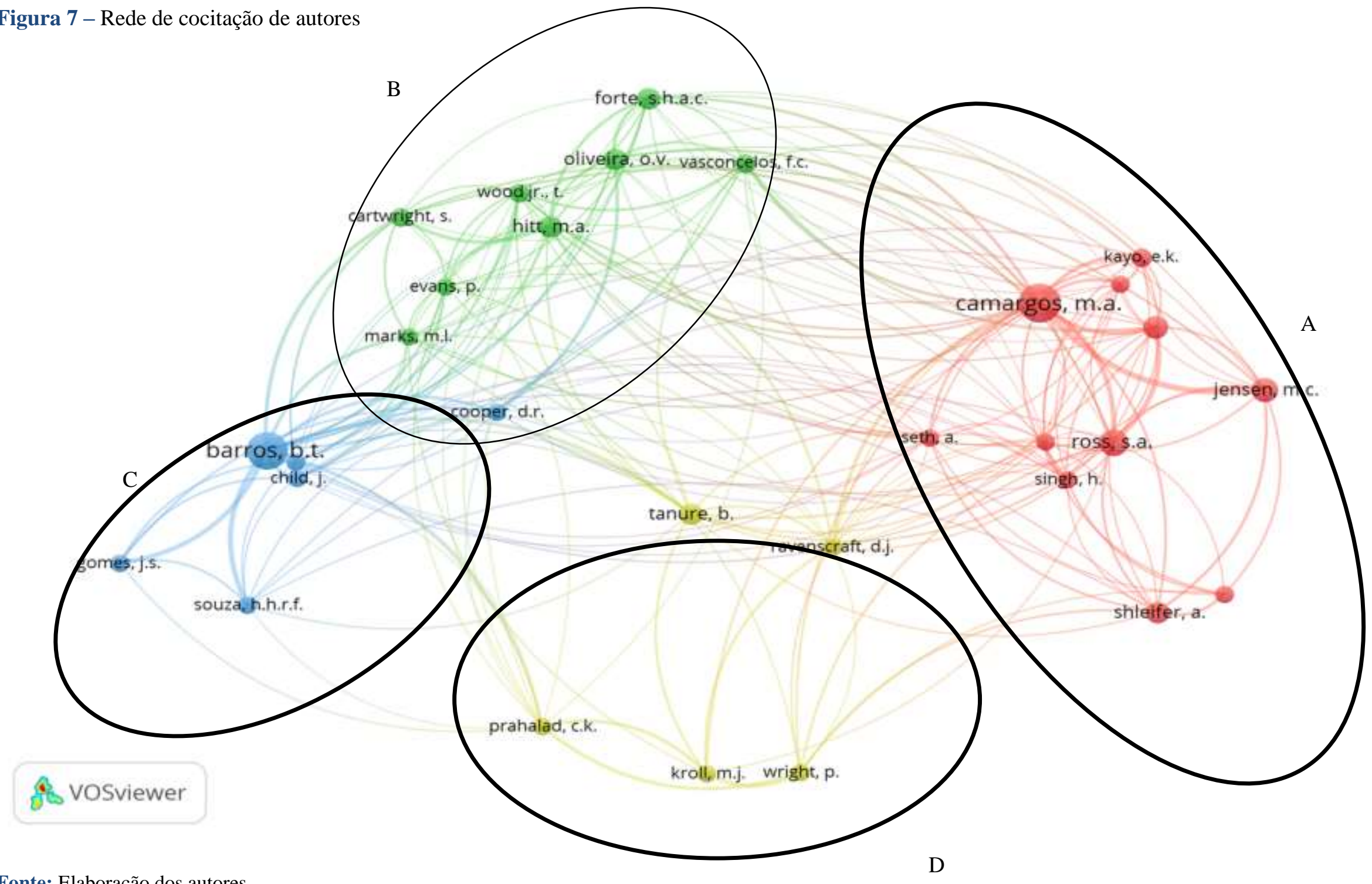

Fonte: Elaboração dos autores. 
A Figura 7 apresenta quatro grupos de cocitações distintos: o primeiro deles ( $\mathrm{A}$ - cor vermelha) é formado por dois estudiosos brasileiros que mais publicaram sobre o assunto (Marcos Antônio de Camargos e Francisco Vidal Barbosa), no tocante ao agrupamento temático de Economia/Finanças, coerente na proximidade e densidade com autores nacionais como Eduardo Kazuo Kayo, cuja abordagem é focada na área de Finanças, juntamente a autores clássicos internacionais de F\&A, na perspectiva econômico-financeira e de Administração Financeira, como Lawrence Gitman, Stephen Ross e Randolph Westerfield. Alguns temas abordados por pesquisadores desse agrupamento são: teoria da firma, como mensurar a criação de valor em F\&A, controle de mercado, determinantes econômicos de F\&A, aquisições hostis e sinergia operacional, teoria da agência e governança corporativa. São encontradas referências mais antigas (desde a década de 1940) até trabalhos mais recentes, o que mantém a proximidade de conteúdos abordados. Como a maioria dos trabalhos possui temáticas correlatas a Finanças e Economia reflete-se o mesmo padrão encontrado nas bases internacionais de periódicos acadêmicos, conforme uma busca na base Web of Science para artigos do campo de Negócios entre 2018 e 2020, com retorno de mais de 300 pesquisas - desse total, mais de 180 são das áreas de Finanças e Economia.

Outro agrupamento de cocitação (B - cor verde) é, na maior parte, composto por autores nacionais (como Thomaz Wood Junior e Flávio Vasconcelos) e alguns internacionais (a exemplo de Sue Cartwright), que discutem sobre F\&A e aspectos como processo de aculturação, gestão de pessoas, integração de pessoas em F\&A, cultura, gestão e estratégia. Além disso, há outros estudiosos que abordam estratégias de modo geral e as voltadas às F\&A (como Michael Hitt) e à gestão internacional de pessoas (Paul Evans), com horizonte temporal de publicação na primeira década dos anos 2000.

$\mathrm{O}$ terceiro agrupamento $(\mathrm{C}-\mathrm{cor}$ azul $)$ é formado por referências, principalmente, das décadas de 1980 e 1990 e do início dos anos 2000, em que Betânia Tanure Barros se destaca com artigos e livros sobre gestão brasileira e F\&A, juntamente a outros coautores e autores - alguns, inclusive, relacionam F\&A com o contexto de gestão e estratégia internacionais. Esse grupo se aproxima do quarto e último conjunto (D - cor amarela) no recorte temporal, ambos com referências da década de 1980 até meados dos anos 2000. O quarto agrupamento é formado por pesquisadores clássicos internacionais de estratégia, como Coimbatore Krishnarao Prahalad, Peter Wright e Mark Kroll, que formam a base de conceitos e aspectos estratégicos para a análise de F\&A.

Verificou-se que alguns temas inerentes às estratégias de F\&A não são frequentemente abordados nos artigos pesquisados, como as $\mathrm{F} \& \mathrm{~A}$ internacionais, os fracassos e as falhas nos processos de F\&A, as peculiaridades desse tipo de estratégia em Pequenas e Médias Empresas (PMEs) e na gestão familiar, apenas para citar alguns aspectos que têm sido contemplados em estudos divulgados nos periódicos internacionais. Neste trabalho, constatou-se um número elevado de artigos direcionados aos casos de estratégias de F\&A que geraram maior repercussão midiática, com menor interesse em pesquisar eventos de $\mathrm{F} \& \mathrm{~A}$ que tiveram menos impacto para o mercado, mas que podem ter grande influência na sociedade. 
Diante das análises realizadas, foi elaborada uma agenda de pesquisa com temas que podem orientar os estudos futuros sobre F\&A. Tais temáticas podem ser o foco de investigações mais robustas, o que possibilitará uma compreensão plural e interdisciplinar das F\&A. Entende-se que as sugestões feitas aqui são um ponto de partida, mas os trabalhos subsequentes não devem estar limitados a ela.

No Quadro 2 é apresentada a agenda de pesquisa resultante desta revisão:

\begin{tabular}{|c|c|}
\hline Categorias Temáticas/Metodológicas & Temas para Estudos Futuros \\
\hline Processo de F\&A & $\begin{array}{l}\text { - Antecedentes da decisão pelas F\&A; } \\
\text { - Fatores e elementos relacionados à implementação de F\&A; } \\
\text { - Estudos dos momentos subsequentes às F\&A. }\end{array}$ \\
\hline Resultados de F\&A & $\begin{array}{l}\text { - Fracassos e falhas nos processos de F\&A; } \\
\text { - Impactos e/ou consequências sociais de estratégias de F\&A; } \\
\text { - Impactos locais e regionais das estratégias de F\&A. }\end{array}$ \\
\hline F\&A e o processo de gestão & $\begin{array}{l}\text { - Desenvolvimento de competências organizacionais e } \\
\text { individuais; } \\
\text { - Aspectos culturais (rituais de identificação, choques e } \\
\text { assimilação, silêncios - tabus); } \\
\text { - Aspectos interculturais ou cross-border; } \\
\text { - Dimensão psicossocial para gestores e funcionários } \\
\text { (sentimentos de luto para alguns e de renovação para outros, } \\
\text { análise da construção da confiança entre pessoas das empresas } \\
\text { envolvidas, resistência e colaboração dos indivíduos de diferentes } \\
\text { níveis hierárquicos às F\&A, impacto de agendas pessoais dos } \\
\text { executivos em decisões de F\&A); } \\
\text { - Dimensão política e das relações de poder; } \\
\text { - Questões de gênero no protagonismo de estratégias de F\&A; } \\
\text { - F\&A vistas como discurso. }\end{array}$ \\
\hline $\begin{array}{l}\text { F\&A em diferentes estruturas e } \\
\text { modelos de gestão }\end{array}$ & $\begin{array}{l}\text { - As estratégias de F\&A envolvendo pequenas e médias empresas } \\
\text { - As implicações da gestão familiar } \\
\text { - Aspectos da F\&A cross-border (elementos definidores das } \\
\text { novas estruturas geradas entre empresas de diferentes países e } \\
\text { continentes) }\end{array}$ \\
\hline Pesquisa em F\&A no Brasil & $\begin{array}{l}\text { - Pesquisas de recorte longitudinal; } \\
\text { - Estudos de casos múltiplos; } \\
\text { - Estudos comparados; } \\
\text { - Questões de gênero e diversidade na publicação nacional de } \\
\text { F\&A; } \\
\text { - Estudos com abordagens críticas. }\end{array}$ \\
\hline
\end{tabular}

Fonte: Elaboração dos autores.

\section{Conclusão}

A análise da produção sobre F\&A em língua portuguesa no Brasil, no período de 2000 a 2018 na área de Administração, mostra que o tema desperta o interesse de diferentes pesquisadores em diversas instituições de ensino, porém não na mesma intensidade em que ocorrem as transações de F\&A no país. Isso permite indagar sobre as negociações que recebem menos atenção da mídia e apresentam menor valor de mercado, mas que podem ter forte influência local e/ou regional a curto e longo prazos. Tais aspectos apontam um distanciamento da academia em relação à dinamicidade dos processos de F\&A e suas consequências para o ambiente social e organizacional. 
Este artigo apresentou o panorama atual de pesquisas em F\&A no Brasil, ao combinar método bibliográfico com a análise integrativa, o que permitiu evidenciar a evolução do quadro teórico no país, os agrupamentos temáticos, as lacunas e as possibilidades de desenvolvimento, com sugestões de agenda para estudos futuros. Com isso, contribui para o avanço do campo de investigações brasileiras sobre F\&A, ao reconhecer os esforços dos diferentes autores e instituições até o momento; destacar temáticas e abordagens; estimular a formação de grupos de pesquisa que contemplam diferentes realidades setoriais e organizacionais, além de parcerias institucionais que promovem a reflexão sobre esse tipo de estratégia e seus desdobramentos para a área de Administração no âmbito nacional.

Destarte, no tocante às limitações para a realização desta pesquisa - cuja fonte de dados foram os artigos de revistas nacionais -, a falta de padronização dos formatos dessas produções e a não indexação em bases de dados internacionais não permitiram a extração de informações de forma automática e estruturada para o uso de programas específicos, voltados à análise da produção acadêmica. Para interpretar tais aspectos, foi necessário tempo e, ainda assim, não se conseguiu gerar uma base de dados completa e consistente, o que impossibilitou alguns tipos de análise e geração de representações gráficas de resultados, como a verificação do acoplamento bibliográfico.

\section{Referências}

Almada, L., \& Policarpo, R. V. S. (2016). A relação entre o estilo de liderança e a resistência à mudança dos indivíduos em um processo de fusão. Revista de Gestão, 23(1), 10-19.

Atz, V., \& Rese, N. (2013). Identificação de elementos culturais na aquisição de uma empresa familiar por um fundo de private equity: um estudo de caso. Revista de Empreendedorismo e Gestão de Pequenas Empresas, 2(2), 73-91.

Bettinazzi, M. L. M., Miller, D., \& Corbetta, M. D. A. G. (2018). Ownership similarity in Mergers and Acquisitions target selection. Strategic Organization, 18(2), 330-361.

Bichara, K. R., \& Camargos, M. A. (2011). Desmutualização, abertura de capital e fusão da Bovespa e BM\&F: uma análise das suas vantagens, desvantagens e consequências. Revista de Administração, Contabilidade e Economia da FUNDACE, 2(2), 1-15.

Binder, M. P., Maccari, E. A., \& Nasser-Carvalho, L. F. (2010). Competência central e lógica dominante: contribuições à análise de processos de fusão e aquisição. Revista de Ciências da Administração, 12(28), 83-104.

Bomfim, E. T., \& Callado, A. L. C. (2016). Análise dos efeitos provocados pelas operações de fusões e aquisições no desempenho econômico-financeiro de empresas brasileiras. Contabilidade Vista \& Revista, 27(3), 105-123.

Borges, C. E. A., Silva, G. A. V., \& Corrêa, M. L. (2009). Mudança na percepção de valor em cooperativas de crédito pós-aglutinação: um estudo de caso. Revista Gestão \& Planejamento, 10(2), 157-178.

Brandão, H. P., Silva, R. A. C. D., Freitas, I. A., Pereira, S. C. M., \& Santos, W. S. F. D. (2013). Gestão de pessoas como fator de sucesso na incorporação da Nossa Caixa pelo Banco do Brasil. Revista de Administração Contemporânea, 17(5), 598-619. 
Camargos, M. A., \& Barbosa, F. V. (2005a). Análise do desempenho econômico-financeiro e da criação de sinergias em processos de fusões e aquisições do mercado brasileiro ocorridos entre 1995 e 1999. Revista de Gestão, 12(2), 99-115.

Camargos, M. A., \& Barbosa, F. V. (2005b). Da fusão Antárctica/Brahma à fusão com a Interbrew: uma análise da trajetória econômico-financeira e estratégica da Ambev. Revista de Gestão, 12(3), 47-63.

Camargos, M. A., \& Barbosa, F. V. (2007). Análise empírica da reação do mercado de capitais brasileiro aos anúncios de fusões e aquisições ocorridos entre 1994 e 2001. RAUSP Management Journal, 42(4), 468-481.

Camargos, M. A., \& Barbosa, F. V. (2010). Fusões e aquisições de empresas brasileiras: sinergias operacionais, gerenciais e rentabilidade. Contabilidade Vista \& Revista, 21(1), 69-99.

Camargos, M. A., \& Minadeo, R. (2007). Aquisições na aviação civil brasileira: uma análise da trajetória da Gol e da Varig até a sua aquisição. Gestão e Sociedade, 1(2), 1-30.

Carvalho, B. O., Garcia, E. A. R., Bizarria, F. P. A., Melo, L. H. A., \& Forte, S. H. A. C. (2014). Aculturação e institucionalização em aquisição internacional no setor automobilístico. Revista de Administração FACES Journal, 13(4), 109-128.

Chueke, G. V., \& Amatucci, M. (2015). O que é bibliometria? Uma introdução ao fórum. InternexTRevista Eletrônica de Negócios Internacionais da ESPM, 10(2), 1-5.

Carmona, C. U. M., \& Araújo, J. P. (2011). Fusões e Aquisições: uma análise teórico-prática à luz dos estudos de caso da Sadia e da Ecodiesel. In 5 Seminário UFPE de Ciências Contábeis. Recife: UFPE.

Falcão, A., \& Muzzio, H. (2013). Antes inimigos, agora um só corpo: perspectivas culturais em um processo de fusão entre concorrentes. Revista Organizações em Contexto, 9(18), 1-23.

Ferreira, T. S. V., \& Callado, A. L. C. (2015). Fusões e Aquisições no Brasil: reflexões acerca da evolução do volume de transações. Revista Pensamento Contemporâneo em Administração, 9(2), 70-83.

Ferreira, M. P., Santos, J. C., Almeida, M. I. R., \& Reis, N. R. (2014). Mergers \& Acquisitions research: a bibliometric study of top strategy and international business journals, 1980-2010. Journal of Business Research, 67(12), 2550-2558.

Fleury, A., \& Fleury, M. T. L. (2012). Multinacionais brasileiras: competências para a internacionalização. Rio de Janeiro: FGV.

Grácio, M. C. C. (2016). Acoplamento bibliográfico e análise de cocitação: revisão teórico-conceitual. Revista Eletrônica de Biblioteconomia e Ciência da Informação, 21(47), 82-99.

Graebner, M. E., Heimeriks, K. H., Huy, Q. N., \& Vaara, E. (2017). The process of postmerger integration: a review and agenda for future research. Academy of Management Annals, 11(1), 1-32.

Haeruddin, M. I. M. (2017). Mergers and Acquisitions: Quo Vadis? Management, 7(2), 84-88.

Hitt, M. A., Ireland, R. D., \& Hoskisson, R. E. (2014). Administração estratégica: competitividade e globalização. (10a ed.). São Paulo: Cengage Learning. 
Hoffmann, V. E., Vieira, D. P., \& Menezes, K. C. M. (2017). Tipos, setores, nacionalidade e experiência: o que importa para o sucesso das estratégias de fusão e aquisição? Revista IberoAmericana de Estratégia, 16(1), 22-37.

Jordão, R. V. D., \& Souza, A. A. (2012). Efeitos da cultura corporativa no sistema de controle gerencial pós-aquisição: um estudo de sucesso numa empresa brasileira. Revista de Gestão, 19(1), 55-71.

Jordão, R. V. D., \& Souza, A. A. (2013). Aquisição de empresas como fator de mudança no sistema de controle gerencial: uma análise estratégica sob a perspectiva da teoria contingencial. Revista Universo Contábil, 9(3), 75-103.

Khan, Z., Soundararajan, V., Wood, G., \& Ahammad, M. F. (2020). Employee emotional resilience during post-merger integration across national boundaries: rewards and the mediating role of fairness norms. Journal of World Business, 55(2), 1-11.

Kobashi, N. Y., \& Santos, R. N. M. (2008). Arqueologia do trabalho imaterial: uma aplicação bibliométrica à análise de dissertações e teses. Revista Eletrônica de Biblioteconomia e Ciência da Informação, 1, 106-115.

Lopes, K. P., \& Oliveira Júnior, M. M. (2002). Estratégias de marcas em processos de aquisição - um estudo de caso exploratório na indústria de alimentos. Revista Administração em Diálogo, 4(1), 1 16.

Macias-Chapula, C. A. (1998). O papel da informetria e da cienciometria e sua perspectiva nacional e internacional. Ciência da Informação, 27(2), 134-140.

Marcondes, C., \& Vantine, J. (2010). A emoção e o seu impacto na integração humana em processos de fusão / aquisição nas organizações. Revista Administração em Diálogo, 12(2), 61-101.

Minadeo, R., \& Camargos, M. A. (2009). Fusões e aquisições no varejo alimentar: uma análise das estratégias de entrada e de crescimento do Carrefour e Wal-Mart no mercado brasileiro. Revista de Ciências da Administração, 11(24), 102-135.

Nogueira, A. J. F. M., \& Silva, O. T. (2014). Transformações organizacionais e gestão de pessoas no setor financeiro. Revista Administração em Diálogo, 16(1), 105-129.

Paul, J., \& Criado, A. R. (2020). The art of writing literature review: what do we know and what do we need to know? International Business Review, 29(4), 107-117.

Pereira, M. F., \& Oliveira, F. V. (2013). O processo de aquisição como estratégia organizacional gerar vantagem competitiva: um estudo de caso no mercado brasileiro de distribuição de combustíveis. Revista de Administração da UFSM, 6(2), 395-414.

Pires, M. G., \& Marcondes, R. C. (2017). Fatores relevantes na integração pós-fusão de Sistemas e Tecnologia da Informação em instituições bancárias brasileiras. Brazilian Business Review, 14(2), 160-181.

PricewaterhouseCoopers Brasil Ltda. (2019). Relatório sobre Fusões e Aquisições no Brasil. Recuperado de https://www.pwc.com.br/pt/estudos/servicos/assessoria-tributaria-societaria/fusoesaquisicoes/2019/fusoes-e-aquisicoes-no-brasil-dezembro-2019.html

Raupp, F. M., \& Warken, R. M. (2009). Utilização da due dilligence em processos de Fusão e Aquisição. Pensar Contábil, 11(45), 34-40. 
Reddy, K. S. (2015). The state of case study approach in Mergers and Acquisitions literature: a bibliometric analysis. Future Business Journal, 1, 13-34.

Reis, E. A. D., Partyka, R. B., Lana, J., \& Marcon, R. (2018). Fusões e aquisições no ensino superior à luz da teoria do crescimento da firma. NAVUS - Revista de Gestão e Tecnologia, 8(4), 37-52.

Shi, W., Sun, J., \& Prescott, J. E. (2012). A temporal perspective of Merger and Acquisition and strategic alliance iniciatives: review and future directions. Journal of Management, 38, 164-209.

Snyder, H. (2019). Literature review as a research methodology: an overview and guidelines. Journal of Business Research, 104, 333-339.

Tanure, B., \& Cançado, V. (2004). Relacionando o motivo da aquisição com diferentes processos de integração cultural. Revista Economia \& Gestão, 4(8), 25-48.

Tanure, B., \& Cançado, V. (2005). Fusões e Aquisições: aprendendo com a experiência brasileira. Revista de Administração de Empresas, 45(2), 10-22.

Toigo, L. A., Hein, N., \& Kroenke, A. (2018). Características predominantes dos mecanismos de governança corporativa e desempenho pós-Fusões e Aquisições no Brasil. Enfoque Reflexão Contábil, 37(4), 85-104.

Torraco, R. J. (2005). Writing integrative literature reviews: guidelines and examples. Human Resource Development Review, 4(1), 356-367.

Tortato, U., Kato, H. T., \& Meyer Junior, V. (2011). Aquisição internacional de empresas: mudança de valores do grupo dirigente. Gestão \& Regionalidade, 27(80), 4-14.

Tortato, U., \& Corso, J. D. (2008). Mudança na configuração estrutural em aquisições de empresa nacional por multinacional. Revista de Administração da Unimep, 6(2), 66-86.

Vieira, L. B., Brito, S. S., Santana, J. R. B., Sanches, S. L. R., \& Galdamez, E. V. C. (2017). Reflexo das operações de Fusões e Aquisições nos indicadores financeiros das empresas brasileiras de capital aberto. Revista de Gestão, 24(3), 235-246.

Vieira, L. D., Calicchio, A. C., \& Zilber, M. A. (2011). O caso LATAM: uma fusão como posicionamento estratégico. Revista Ciências Administrativas, 17(2), 465-488.

Viglioni, M. T. D., Carvalho, F. M., Benedicto, G. C., \& Prado, J. W. (2018). Indicadores econômicofinanceiros determinantes de Fusões e Aquisições: um estudo na indústria de tecnologia no brasil. Contabilidade, Gestão e Governança, 21(3), 420-438.

Vogel, R., \& Güttel, W. H. (2013). The dynamic capability view in strategic management: a bibliometric review. International Journal of Management Reviews, 15(4), 426-446.

Welch, X., Pavićević, S., Keil, T., \& Laamanen, T. (2020). The pre-deal phase of Mergers and Acquisitions: a review and research agenda. Journal of Management, 46(6), 843-878.

Worek, M. (2017). Mergers and Acquisitions in family business: current literature and future insights. Journal of Family Business Management, 7(2), 177-206.

Zilber, M. A., \& Piekny, E. E. (2005). Estratégia de fusões e aquisições: eficácia na expansão das plataformas de produtos em empresas de autopeças. Revista de Administração Contemporânea, 9(3), 169-191. 